\title{
Sitting Behaviors and Mental Health among Workers and Nonworkers: The Role of Weight Status
}

\author{
Karin I. Proper, H. Susan J. Picavet, Wanda J. E. Bemelmans, W. M. Monique Verschuren, \\ and G. C. Wanda Wendel-Vos
}

National Institute for Public Health and the Environment, Centre for Prevention and Health Services Research, P.O. Box 1, 3720 BA Bilthoven, The Netherlands

Correspondence should be addressed to Karin I. Proper, karin.proper@rivm.nl

Received 7 June 2011; Revised 5 September 2011; Accepted 26 September 2011

Academic Editor: Dale Bond

Copyright () 2012 Karin I. Proper et al. This is an open access article distributed under the Creative Commons Attribution License, which permits unrestricted use, distribution, and reproduction in any medium, provided the original work is properly cited.

\begin{abstract}
Objective. To explore the associations between sitting time in various domains and mental health for workers and nonworkers and the role of weight status. Design. Cross-sectional analyses were performed for 1064 respondents (47\% men, mean age 59 years) from the Doetinchem Cohort Study 2008-2009. Sedentary behavior was measured by self-reported time spent sitting during transport, leisure time, and at work. Mental health was assessed by the Mental Health Inventory (MHI-5). BMI was calculated based on measured body height and weight. Results. Neither sitting time during transport nor at work was associated with mental health. In the working population, sitting during leisure time, and particularly TV viewing, was associated with poorer mental health. BMI was an effect modifier in this association with significant positive associations for healthy-weight non-workers and obese workers. Conclusion. Both BMI and working status were effect modifiers in the relation between TV viewing and mental health. More longitudinal research is needed to confirm the results and to gain insight into the causality and the underlying mechanisms for the complex relationships among sedentary behaviors, BMI, working status, and mental health.
\end{abstract}

\section{Introduction}

In the past, advances in technology have caused a decrease in the time spent on physical activities and an increase in the time spent on sedentary behaviors [1]. For instance, viewing television (TV) and spending time on the computer keep both adults and children sedentary for many hours each day [2-5]. The etiology of obesity is complex and includes biologic, genetic, and behavioral contributors; however, the obesogenic environment that promotes a sedentary lifestyle plays an important role in the obesity epidemic $[6,7]$. What is known about the health implications of sedentary behaviors, including weight outcomes and obesity, is summarized in several reviews. Based on cross-sectional studies, previous reviews concluded that there were generally positive associations between viewing TV and indicators of overweight $[8,9]$. However, recent reviews of prospective studies are inconclusive, partly due to the poor methodological quality of the studies and conflicting results among the studies [10-12]. For other obesity-related health outcomes, that is, type 2 diabetes and mortality from all causes, and cardiovascular diseases (CVD), moderate to strong evidence was found for the longitudinal impact of sedentary behavior [11].

Although the research on sedentary behavior has been dominated by studies on its association with physical health, there is increasing research focusing on the association between sedentary behavior and mental health, especially depression [13-16]. A recent review showed positive associations between sedentary behaviors and the risk of depression among adults based on seven observational studies, while four intervention studies showed contradictory results [14]. In addition to depression, there are other common mental health measures, including anxiety and general mental health or mental well-being. However, the link between sedentary behavior and general mental health outcomes has received scant attention [17].

Among the Dutch population, there is a $14 \%$ yearly prevalence of self-reported poor mental health (defined by the Mental Health Inventory, MHI-5 $\leq 60)$ [18]. Considering the 
public health impact of poor mental health, insight into the association with sedentary behavior is relevant. Among adults, Hamer and colleagues (2010) found that recreational sedentary behavior by adults, defined by TV- and screenbased activity, was associated with poorer mental health scores [13].

Most studies on sedentary behaviors have focused on TV viewing. However, sedentary behaviors involve domains other than sitting during leisure, such as sitting at work or sitting during transport. Among working adults, who represent a major part of the adult population, a significant amount of time is spent at work, and the majority of their total sitting time each day is likely to be at work due to the organization of the work $[2,3]$.

With respect to the observed associations between TV viewing and mental health, several explanations can be proposed. In addition to possible physiologic mechanisms, there are possible behavioral explanations; for example, extended time spent viewing TV may lead to social isolation which adversely affects mental well-being [19]. Another possible explanation is the documented association between TV viewing and unhealthy (snack) food and beverage intake $[20,21]$. With respect to the other side of energy balance, it has been hypothesized that TV viewing or other leisuretime sedentary behaviors may be substituted for beneficial physical activity that reduces the risk of depression [22]. Thus, TV viewing may be related to poorer mental health through reduced physical activity and obesity [20, 22-24]. It is yet unknown whether these associations also hold true for sedentary behaviors in other domains. For instance, for workers, is the relationship between sitting at work and mental health similar to TV viewing? Also, it is unknown whether the association between sedentary behavior and mental health is the same for workers and nonworkers. To date, evidence on these associations is lacking despite the relevance to reduce obesity and improve mental health.

Due to the current lack of knowledge on the relationship between various sedentary behaviors and mental health, the aim of this study was to explore the association between domain-specific sitting with mental health among workers and nonworkers. Weight status has shown to be associated with sedentary behaviors $[8,9]$, as well as with mental health problems [23, 25]; but the role of weight status in this association is yet unknown. Therefore, the second aim of the present study was to explore the role of weight status in the relationship between the various sedentary behaviors and mental health.

\section{Methods}

2.1. Participants. Data were derived from the Doetinchem Cohort Study, a Dutch, prospective, population-based study among residents from a town (Doetinchem) in the Netherlands. The data collection began among persons aged 2059 years from 1987 to 1991 as part of the Monitoring Project on Cardiovascular Disease Risk Factors [26]. The cohort is reexamined every five years, and the fifth round (2008-2012) is ongoing. The measurements of the total study population are completed within a 5-year time frame, and each participant is measured every five years. Response rate was $62 \%$ in the first round, and varied between 75 and $79 \%$ in subsequent rounds. Starting with the fifth round, data have been collected about the time spent on sedentary behaviors. Since the data collection of the fifth wave is ongoing, only data from the first two years (2008 and 2009) are used in this study.

2.2. Procedure. The general aim of the Doetinchem Cohort Study is to study the impact of (changes in) lifestyle behaviors and biological risk factors on health outcomes during ageing [27]. Measurements were made via an extensive questionnaire and physical examination. All participants gave written informed consent and the study complied with Helsinki Declaration guidelines. Detailed information about sampling and data collection procedures has been described elsewhere [27].

\subsection{Measures}

2.3.1. Sedentary Behavior. Sedentary behavior was assessed by self-reported time spent sitting during a usual week over the past 12 months. The format of the sitting-time questions was similar to the questions about physical activity, which were designed for the European Investigation into Cancer and Nutrition (EPIC) [28]. The participants were asked to report their weekly sitting time (in hours) spent:

(1) traveling by motor vehicle (such as train, bus, car, tram, motorbike, motor) during
(a) commuting,
(b) work,
(c) leisure;

(2) sitting at work (behind desk, computer, or meeting);

(3) sitting during leisure time while

(a) reading and/or studying,

(b) TV viewing,

(c) sitting behind the computer,

(d) other sitting activities (talking with friends, playing games, listening to music, etc.).

From these items, three subscores were calculated by totaling the time spent sitting in each category: hours per week sitting during transport either for work or leisure time, hours per week sitting during work, and hours per week sitting during leisure time (either reading or studying, viewing television, computer time, or other sitting activities). Sitting time per domain was calculated only in those cases for which all underlying sitting activities were not missing. In all other cases, sitting time for the specific domain was considered as missing. Further, the time reported on each sitting activity was maximized at eight hours per day and seven days per week (five days/week for sitting at work) before calculating sitting time per domain. The total time 
spent sitting during the day was calculated by summing up the time spent sitting in the three domains, that is, transport, at work, and in leisure time. Again, total sitting time was calculated only in those cases for which all underlying domains of sitting were not missing. In all other cases, total sitting time was considered as missing.

2.3.2. Mental Health. Mental health was measured by the Mental Health Inventory (MHI-5), a subscale of the RAND 36 [29]. The MHI-5 is used to measure general mental health during the past month $[17,29]$ and has been found to be a valid and reliable measure of mental health status $[29,30]$. The MHI-5 has five questions about feelings of depression and nervousness to be answered on a six-point scale ranging from "all of the time" [1] to "none of the time" [6]. The mental health score ranged from 0 to 100 points, calculated by first reversing the coding of the two positively formulated questions and consequently summing the points of each item $-5 / 25 * 100$, with a higher score reflecting better mental health. A dichotomous variable was created using a cutoff point of $60[29,31]$, indicating poor $(\leq 60)$ versus good $(>60)$ mental health.

2.3.3. Work Status. Using a single question, the respondents were asked whether they had paid work at the moment of the measurement. They could answer on a seven point scale with answers including "yes, as an employee (payroll)," "yes, self-employed," "no, I am housewife/man," "no, I am unemployed," "no, I am retired," "no, I am disabled," and "other". For the analyses, those working as an employee and self-employed were considered as a worker, while the remaining respondents, including "other," were treated as nonworkers.

2.3.4. Body Mass Index. Body weight and height were measured during a physical examination by trained assistants at the Municipal Health Services with participants wearing light indoor clothing, with emptied pockets and no shoes [27]. Body weight was assessed with a SECA balance scale to the nearest $100 \mathrm{~g}$ on a calibrated scale. Body height was measured with a stadiometer mounted to the wall while participants stood straight against a wall, with their feet at a 45-degree angle, to an accuracy of $0.5 \mathrm{~cm}$. Both the SECA balance scale and the height stadiometer were calibrated each year. Body Mass Index was calculated by body weight in kilograms divided by body height in meters squared. Subsequently, BMI was categorized as healthy weight (BMI 18.5$24.9 \mathrm{~kg} / \mathrm{m}^{2}$ ), moderately overweight (BMI $25-29.9 \mathrm{~kg} / \mathrm{m}^{2}$ ), and obese $\left(\mathrm{BMI} \geq 30 \mathrm{~kg} / \mathrm{m}^{2}\right)$. Those participants who were underweight $\left(B M I<18.5 \mathrm{~kg} / \mathrm{m}^{2}\right)(n=3)$ were excluded from the present analyses.

2.3.5. Covariates. Potential confounders of the association between sitting and mental health were assessed by means of self-administered questionnaires. Sociodemographic variables included gender, age (in years), and educational level. Educational level was assessed by the highest schooling achieved and was subsequently classified as low (interme- diate secondary school or less), moderate (intermediate vocational or higher secondary education), or high (higher vocational education or university). Household composition was assessed by the question: "with which persons are you currently living together" using six answer categories: "not applicable," "I live alone," "with a partner," "with children up to 18 years of age," "with children 18 years or older," "with my parents" or "with other adults"). A dichotomous variable was created to distinguish participants living alone from participants living with others. Perceived general health was measured using a question from the RAND 36 [29, 30], which was dichotomized as "healthy" (including the answers "excellent," "very well," or "good") or "unhealthy" (including the answers "mediocre" or "bad"). Lifestyle behaviors included: physical activity, smoking, and alcohol consumption. Smoking status was defined as never, current, or former smoker. Data on alcohol consumption were categorized as 0 glasses/week, 1-2 (women) or 1-3 (men) glasses/week, or $\geq 2$ (women) or $\geq 3$ (men) glasses/week. An extended version of the physical activity questionnaire designed for the European Prospective Investigation into Cancer and Nutrition (EPIC) was used. This questionnaire included items on time spent on leisure-time activities (walking, bicycling, odd jobs, and gardening) during the summer and then during the winter [28]. For these activities, the lowest amount of time reported during either summer or winter was used in order to cautiously estimate physical activity levels. In addition, the questionnaire included items on sports and occupational activity irrespective of season. All reported sports were provided with a MET-value according to Ainsworth's updated compendium of physical activities [32]. Total time (hours/week) spent on moderately intense (4.0-6.5 METs) physical activity was calculated by taking the sum of the time reported on bicycling, gardening, sports (4.0-6.5 METs), and moderately intense activity at work (i.e., walking regularly while carrying heavy objects). Time (hours/week) spent on vigorous ( $\geq 6.5$ METs) physical activity was calculated by taking the sum of the time reported for sports ( $\geq 6.5 \mathrm{METs})$. In addition, participants were categorized as either "adhering" ( $\geq 3.5$ hours/week of at least moderate physical activity) or "not adhering" to the physical activity guideline [33].

2.4. Statistics. Data were available for 1588 men and women, aged 41 to 80 years old, examined in 2008-2009. Participants with missing values for outcome variables and confounders were excluded from the analyses $(n=521)$. In addition, participants who were underweight $(n=3)$ were excluded, leaving 1064 men and women for the analyses.

Descriptive characteristics (mean and standard deviation or percentage) for all key variables were calculated for the study population as a whole and stratified by working status. The association between sitting time and mental health was determined using a linear regression analysis with the total or domain-specific time spent sitting as the independent variable and the mental health score as the dependent variable. Analyses were stratified by working status. Both crude and adjusted analyses were performed. To explore 
TABLE 1: Characteristics of the study population $(n=1064)$.

\begin{tabular}{|c|c|c|c|}
\hline & $\begin{array}{c}\text { Total } N=1064 \\
\text { Mean } \pm \mathrm{SD}\end{array}$ & $\begin{array}{c}\text { Working } N=513 \\
\text { Mean } \pm \mathrm{SD}\end{array}$ & $\begin{array}{c}\text { Not working } N=551 \\
\text { Mean } \pm \mathrm{SD}\end{array}$ \\
\hline Age (years) & $59 \pm 9$ & $52 \pm 6$ & $66 \pm 8$ \\
\hline Gender (\% men $)$ & 47.0 & 54.2 & 45.8 \\
\hline Education (\% higher level) & 23.1 & 27.3 & 19.2 \\
\hline Household composition (\% living alone) & 13.8 & 9.0 & 18.3 \\
\hline Occupational status (\% working) & 48.2 & - & - \\
\hline Perceived general health (\% healthy) & 86.6 & 92.4 & 81.1 \\
\hline Physical activity $(\mathrm{h} / \mathrm{wk})^{1}$ & $22.5 \pm 14.5$ & $22.3 \pm 15.8$ & $22.8 \pm 13.2$ \\
\hline Physical activity (\% active) & 58.9 & 61.4 & 56.6 \\
\hline Smoking (\% smoker) & 17.3 & 23.0 & 12.0 \\
\hline Alcohol (\% moderate consumption $)^{2}$ & 55.7 & 60.8 & 51.0 \\
\hline Total sitting time $(\mathrm{h} / \mathrm{wk})$ & $40.9 \pm 19.7$ & $47.9 \pm 21.3$ & $34.4 \pm 15.4$ \\
\hline \multicolumn{4}{|l|}{ Domain-specific sitting time } \\
\hline Transport (h/wk) & $5.2 \pm 6.3$ & $7.4 \pm 7.8$ & $3.1 \pm 3.3$ \\
\hline (i) Commuting or during work (h/wk) & $2.5 \pm 5.6$ & $5.2 \pm 7.2$ & - \\
\hline (ii) Leisure $(\mathrm{h} / \mathrm{wk})$ & $2.7 \pm 2.7$ & $2.2 \pm 1.9$ & $3.1 \pm 3.3$ \\
\hline At work (h/wk) & $7.4 \pm 12.3$ & $15.4 \pm 13.8$ & - \\
\hline Leisure (h/wk) & $28.3 \pm 13.8$ & $25.1 \pm 11.9$ & $31.3 \pm 14.8$ \\
\hline (i) Reading (h/wk) & $5.5 \pm 5.8$ & $4.5 \pm 4.4$ & $6.5 \pm 6.7$ \\
\hline (ii) TV viewing $(\mathrm{h} / \mathrm{wk})$ & $13.4 \pm 8.3$ & $11.6 \pm 7.1$ & $15.0 \pm 8.9$ \\
\hline (iii) Using computer (h/wk) & $3.8 \pm 5.1$ & $4.0 \pm 4.7$ & $3.5 \pm 5.4$ \\
\hline (iv) Other sitting (h/wk) & $5.6 \pm 5.5$ & $5.0 \pm 4.3$ & $6.3 \pm 6.4$ \\
\hline Mental health (score 0-100) & $79.9 \pm 14.4$ & $81.1 \pm 14.3$ & $78.8 \pm 14.4$ \\
\hline Mental health (\% healthy) & 88.6 & 90.1 & 87.3 \\
\hline BMI $\left(\mathrm{kg} / \mathrm{m}^{2}\right)$ & $26.8 \pm 4.1$ & $26.2 \pm 3.8$ & $27.3 \pm 4.2$ \\
\hline$\%$ healthy weight & 35.6 & 41.7 & 29.9 \\
\hline$\%$ moderately overweight & 46.6 & 44.8 & 48.3 \\
\hline$\%$ obese & 17.8 & 13.5 & 21.8 \\
\hline
\end{tabular}

${ }^{1}$ Total physical activity, including light-, moderate-, and vigorous-intensity physical activity;

${ }^{2}$ moderate alcohol consumption is defined as 1-2 glasses per day for women and 1-3 glasses/day for men.

the role of BMI in the association, three adjusted models were applied. One included all covariates (i.e., gender, age, education, household composition, perceived health, physical activity, smoking, and alcohol) but excluded BMI (Model 1); one included all covariates and BMI (Model 2); and included an interaction term between sitting time and BMI (Model 3). The same linear regression analyses were then performed but stratified for weight status as defined by the BMI categories (healthy weight, moderate overweight, and obese adults). All analyses were performed using the SAS program, version 9.2 (SAS-Institute, Cary, NC, USA).

\section{Results}

3.1. Study Population. The mean age of the respondents was 59 years; the mean age of workers was 52 years versus 66 years for nonworkers (Table 1). The majority perceived their health as at least good, and $88.6 \%$ of the respondents were mentally healthy, although this was slightly higher for the working population, 90.1\%. The mean BMI was
$26.8 \mathrm{~kg} / \mathrm{m}^{2}$, and $44.8 \%$ of the working population and $48.3 \%$ of the nonworking population were moderately overweight. Approximately $13.5 \%$ of workers were obese versus $21.8 \%$ of nonworkers (Table 1). On average, the total time spent sitting across the domains was 40.9 hours per week with higher sitting times for workers than for nonworkers $(47.9 \mathrm{hr} / \mathrm{wk}$ versus $34.3 \mathrm{hr} / \mathrm{wk}$ among nonworkers). Workers spent on average over 15 hours per week sitting while at work. The respondents spent most of their sitting time in leisure with an average of 28.3 weekly hours $(25.1 \mathrm{hr} / \mathrm{wk}$ for workers, $31.3 \mathrm{hr} / \mathrm{wk}$ for nonworkers). TV viewing accounted for the majority of leisure sitting time ranging from 11.6 to 15.0 hours per week.

3.2. Association between Sitting Time and Mental Health. No association was found for sitting during transport or for sitting at work and mental health. For time sitting during transport, there was a significant negative interaction with BMI for the working population $(P<0.05)$ (Table 2$)$. Among workers, the time spent sitting in leisure, and particularly 
TABLE 2: The association between sitting time and mental health stratified by work status: results of the linear regression analysis.

\begin{tabular}{|c|c|c|c|c|c|c|}
\hline & \multicolumn{6}{|c|}{ Association with mental health ${ }^{1}$} \\
\hline & \multicolumn{2}{|c|}{ Crude } & \multicolumn{2}{|c|}{ Adjusted $^{2}$} & \multicolumn{2}{|c|}{ Adjusted $^{3}$} \\
\hline & Beta & $95 \% \mathrm{CI}$ & Beta & $95 \% \mathrm{CI}$ & Beta & $95 \% \mathrm{CI}$ \\
\hline \multicolumn{7}{|l|}{ Working $(n=513)$} \\
\hline Total & -0.04 & $-0.10 ; 0.02$ & -0.05 & $-0.12 ; 0.01$ & -0.05 & $-0.12 ; 0.01$ \\
\hline Transport (h/wk) & -0.10 & $-0.26 ; 0.06$ & -0.13 & $-0.29 ; 0.04$ & -0.13 & $-0.29 ; 0.04$ \\
\hline (i) Commuting or during work (h/wk) & -0.10 & $-0.27 ; 0.07$ & -0.16 & $-0.34 ; 0,02$ & $-0.15^{5}$ & $-0.33 ; 0.03$ \\
\hline (ii) Leisure (h/wk) & -0.29 & $-0.95 ; 0.37$ & 0.04 & $-0.61 ; 0.68$ & 0.05 & $-0.60 ; 0.70$ \\
\hline At work $(\mathrm{h} / \mathrm{wk})$ & 0.04 & $-0.05 ; 0.13$ & 0.01 & $-0.09 ; 0.11$ & 0.01 & $-0.09 ; 0.11$ \\
\hline Leisure (h/wk) & -0.13 & $-0.24 ;-0.03$ & -0.11 & $-0.21 ;-0.01$ & -0.11 & $-0.21 ;-0.002$ \\
\hline (i) Reading (h/wk) & 0.07 & $-0.21 ; 0.35$ & 0.15 & $-0.14 ; 0.44$ & 0.15 & $-0.13 ; 0.44$ \\
\hline (ii) TV viewing (h/wk) & -0.20 & $-0.38 ;-0.03$ & -0.19 & $-0.35 ;-0.02$ & -0.18 & $-0.35 ;-0.01$ \\
\hline (iii) Using computer (h/wk) & -0.21 & $-0.48 ; 0.05$ & -0.23 & $-0.49 ; 0.02$ & -0.23 & $-0.49 ; 0.03$ \\
\hline (iv) Other sitting (h/wk) & -0.28 & $-0.57 ; 0.01$ & -0.16 & $-0.44 ; 0.12$ & -0.16 & $-0.44 ; 0.12$ \\
\hline \multicolumn{7}{|l|}{ Nonworking $(n=551)$} \\
\hline Total & 0.04 & $-0.04 ; 0.11$ & 0.003 & $-0.07 ; 0.08$ & $0.004^{4}$ & $-0.07 ; 0.08$ \\
\hline Transport (h/wk) & 0.05 & $-0.31 ; 0.42$ & -0.14 & $-0.50 ; 0.22$ & -0.13 & $-0.49 ; 0.23$ \\
\hline (i) Commuting or during work ( $\mathrm{h} / \mathrm{wk}$ ) & - & & - & & - & \\
\hline (ii) Leisure $(\mathrm{h} / \mathrm{wk})$ & 0.05 & $-0.31 ; 0.42$ & -0.14 & $-0.50 ; 0.22$ & -0.13 & $-0.49 ; 0.23$ \\
\hline At work $(\mathrm{h} / \mathrm{wk})$ & - & & - & & - & \\
\hline Leisure (h/wk) & 0.03 & $-0.05 ; 0.12$ & 0.01 & $-0.07 ; 0.09$ & $0.01^{4}$ & $-0.07 ; 0.09$ \\
\hline (i) Reading (h/wk) & 0.16 & $-0.02 ; 0.34$ & 0.01 & $-0.18 ; 0.19$ & $-0.01^{4}$ & $-0.19 ; 0.18$ \\
\hline (ii) TV viewing (h/wk) & -0.09 & $-0.22 ; 0.05$ & -0.04 & $-0.17 ; 0.09$ & -0.04 & $-0.17 ; 0.09$ \\
\hline (iii) Using computer (h/wk) & 0.32 & $0.10 ; 0.54$ & 0.16 & $-0.07 ; 0.39$ & 0.17 & $-0.06 ; 0.40$ \\
\hline (iv) Other sitting (h/wk) & -0.05 & $-0.23 ; 0.14$ & 0.03 & $-0.16 ; 0.21$ & 0.03 & $-0.15 ; 0.22$ \\
\hline
\end{tabular}

${ }^{1}$ A higher MHI score indicates better mental health; thus, a negative beta indicates a negative association between sitting time and mental health; ${ }^{2}$ Adjusted for gender, age, education, household composition, perceived health, physical activity, smoking, and alcohol consumption; ${ }^{3}$ additionally adjusted for BMI; ${ }^{4}$ when added to this model: $P \leq 0.05$ for a positive interaction term; ${ }^{5}$ when added to this model: $P \leq 0.05$ for a negative interaction term.

the time spent viewing TV, was negatively associated with mental health, both with and without adjustment for BMI $(\beta-0.11,95 \%$ CI $(-0.21)-(-0.002)$ for total leisure time, and $\beta-0.18,95 \% \mathrm{CI}(-0.35)-(-0.01)$ for TV viewing time, resp.). Among the nonworking population, no significant association between total time sitting, or sitting during leisure and mental health was found. However, a significant positive interaction with BMI was apparent for the total time spent sitting and leisure-time sitting $(P<0.05)$.

3.3. The Role of Weight Status in the Association between Sitting Time and Mental Health. Tables 3(a) and 3(b) present the results of the linear regression models for the association between the sitting time variables and mental health stratified by the three weight-status groups for the working (Table 3(a)) and nonworking populations (Table 3(b)), respectively. Among the obese workers, a significant negative association was found for the time spent viewing TV (model 2: $\beta-0.43,95 \%$ CI $(-0.84)-(-0.02)$ ). Adjustment for BMI (model 3 ) did not change the significant negative association (model 3: $\beta-0.42,95 \%$ CI $(-0.83)-(-0.01))$. There was no association between sitting time and mental health for the healthy weight or moderately overweight workers. Analyses among the nonworking population showed that total time sitting $(\beta-0.16,95 \% \mathrm{CI}$ $(-0.29)-(-0.02))$ and the time spent sitting during leisure $(\beta-0.17,95 \% \mathrm{CI}(-0.30)-(-0.03))$ and viewing TV $(\beta-0.34$, $95 \%$ CI $(-0.58)-(-0.11))$ were all negatively associated with mental health for healthy-weight persons but not among the moderately overweight or obese persons (Table 3(b)). Among the moderately overweight and obese nonworkers, no significant associations between sitting time and mental health were observed.

\section{Discussion}

The results of this explorative study showed no association between time spent sitting during transport or sitting at work and mental health. Only sitting during leisure time and in particular the amount of time viewing TV were associated with a poorer mental health in the working population. Associations were even more complicated, because both work status and weight status are effect modifiers in these associations. Among nonworking persons, the total time spent sitting, the time spent sitting during leisure, and particularly viewing $\mathrm{TV}$, was associated with a poorer mental health in those with a healthy weight only. In workers, the 
TABLE 3

(a) The association between sitting time and mental health among the working population $(n=513)$ stratified by weight status: results of the linear regression analysis.

\begin{tabular}{|c|c|c|c|c|c|c|}
\hline & \multicolumn{6}{|c|}{ Association with mental health ${ }^{1}$} \\
\hline & \multicolumn{2}{|c|}{ Crude } & \multicolumn{2}{|c|}{ Adjusted $^{2}$} & \multicolumn{2}{|c|}{ Adjusted $^{3}$} \\
\hline & Beta & $95 \%$ CI & Beta & 95\% CI & Beta & $95 \%$ CI \\
\hline \multicolumn{7}{|l|}{ Healthy weight $(n=214)$} \\
\hline Total & -0.06 & $-0.15 ; 0.03$ & -0.09 & $-0.19 ; 0.01$ & -0.10 & $-0.19 ; 0.003$ \\
\hline Transport (h/wk) & 0.03 & $-0.24 ; 0.29$ & -0.03 & $-0.32 ; 0.25$ & -0.02 & $-0.31 ; 0.27$ \\
\hline (i) Commuting or during work (h/wk) & 0.03 & $-0.26 ; 0.31$ & -0.06 & $-0.37 ; 0.25$ & -0.05 & $-0.36 ; 0.27$ \\
\hline (ii) Leisure (h/wk) & 0.10 & $-1.12 ; 1.31$ & 0.36 & $-0.86 ; 1.58$ & 0.36 & $-0.86 ; 1.57$ \\
\hline At work $(\mathrm{h} / \mathrm{wk})$ & -0.07 & $-0.21 ; 0.06$ & -0.09 & $-0.25 ; 0.06$ & -0.11 & $-0.26 ; 0.04$ \\
\hline Leisure (h/wk) & -0.10 & $-0.25 ; 0.06$ & -0.11 & $-0.26 ; 0.04$ & -0.11 & $-0.26 ; 0.04$ \\
\hline (i) Reading (h/wk) & -0.05 & $-0.46 ; 0.36$ & -0.004 & $-0.44 ; 0.43$ & -0.02 & $-0.45 ; 0.42$ \\
\hline (ii) TV viewing (h/wk) & -0.02 & $-0.29 ; 0.26$ & -0.11 & $-0.38 ; 0.17$ & -0.10 & $-0.38 ; 0.17$ \\
\hline (iii) Using computer (h/wk) & -0.19 & $-0.63 ; 0.25$ & -0.27 & $-0.72 ; 0.18$ & -0.28 & $-0.73 ; 0.17$ \\
\hline (iv) Other sitting (h/wk) & -0.45 & $-0.88 ;-0.03$ & -0.35 & $-0.77 ; 0.07$ & -0.34 & $-0.77 ; 0.08$ \\
\hline \multicolumn{7}{|l|}{ Moderately overweight $(n=230)$} \\
\hline Total & -0.01 & $-0.10 ; 0.08$ & -0.03 & $-0.13 ; 0.07$ & -0.03 & $-0.13 ; 0.07$ \\
\hline Transport (h/wk) & -0.15 & $-0.40 ; 0.09$ & -0.20 & $-0.45 ; 0.05$ & -0.19 & $-0.44 ; 0.06$ \\
\hline (i) Commuting or during work (h/wk) & -0.14 & $-0.40 ; 0.13$ & -0.20 & $-0.48 ; 0.07$ & -0.19 & $-0.47 ; 0.08$ \\
\hline (ii) Leisure (h/wk) & -0.55 & $-1.48 ; 0.37$ & -0.35 & $-1.26 ; 0.56$ & -0.36 & $-1.27 ; 0.55$ \\
\hline At work $(\mathrm{h} / \mathrm{wk})$ & 0.10 & $-0.04 ; 0.24$ & 0.04 & $-0.11 ; 0.19$ & 0.04 & $-0.11 ; 0.19$ \\
\hline Leisure (h/wk) & -0.11 & $-0.29 ; 0.06$ & -0.07 & $-0.24 ; 0.11$ & -0.06 & $-0.24 ; 0.11$ \\
\hline (i) Reading (h/wk) & 0.34 & $-0.19 ; 0.86$ & 0.46 & $-0.08 ; 1.00$ & 0.47 & $-0.07 ; 1.00$ \\
\hline (ii) TV viewing (h/wk) & -0.19 & $-0.47 ; 0.10$ & -0.12 & $-0.40 ; 0.16$ & -0.11 & $-0.39 ; 0.17$ \\
\hline (iii) Using computer (h/wk) & -0.29 & $-0.69 ; 0.12$ & -0.33 & $-0.73 ; 0.07$ & -0.32 & $-0.72 ; 0.07$ \\
\hline (iv) Other sitting (h/wk) & -0.17 & $-0.63 ; 0.29$ & -0.01 & $-0.46 ; 0.43$ & -0.03 & $-0.48 ; 0.41$ \\
\hline \multicolumn{7}{|l|}{ Obese $(n=69)$} \\
\hline Total & -0.08 & $-0.23 ; 0.06$ & -0.07 & $-0.25 ; 0.12$ & -0.04 & $-0.24 ; 0.15$ \\
\hline Transport (h/wk) & -0.20 & $-0.58 ; 0.17$ & -0.16 & $-0.60 ; 0.27$ & -0.14 & $-0.58 ; 0.30$ \\
\hline (i) Commuting or during work (h/wk) & -0.24 & $-0.66 ; 0.18$ & -0.23 & $-0.70 ; 0.23$ & -0.21 & $-0.68 ; 0.26$ \\
\hline (ii) Leisure (h/wk) & -0.18 & $-1.92 ; 1.56$ & 1.01 & $-1.16 ; 3.17$ & 1.07 & $-1.10 ; 3.23$ \\
\hline At work $(\mathrm{h} / \mathrm{wk})$ & 0.09 & $-0.17 ; 0.34$ & 0.12 & $-0.22 ; 0.47$ & 0.17 & $-0.19 ; 0.52$ \\
\hline Leisure (h/wk) & -0.24 & $-0.48 ; 0.002$ & -0.17 & $-0.45 ; 0.11$ & -0.15 & $-0.44 ; 0.14$ \\
\hline (i) Reading (h/wk) & -0.03 & $-0.63 ; 0.56$ & 0.26 & $-0.46 ; 0.98$ & 0.33 & $-0.41 ; 1.06$ \\
\hline (ii) TV viewing (h/wk) & -0.50 & $-0.86 ;-0.13$ & -0.43 & $-0.84 ;-0.02$ & -0.42 & $-0.83 ;-0.01$ \\
\hline (iii) Using computer (h/wk) & -0.09 & $-0.72 ; 0.54$ & -0.09 & $-0.75 ; 0.56$ & -0.10 & $0.76 ; 0.55$ \\
\hline (iv) Other sitting (h/wk) & -0.13 & $-0.86 ; 0.61$ & 0.004 & $-0.82 ; 0.83$ & 0.12 & $-0.74 ; 0.98$ \\
\hline
\end{tabular}

${ }^{1}$ A higher MHI score indicates better mental health; thus a negative beta indicates a negative association between sitting time and mental health; ${ }^{2}$ adjusted for gender, age, education, household composition, perceived health, physical activity, smoking, and alcohol consumption; ${ }^{3}$ additionally adjusted for BMI.

(b) The association between sitting time and mental health among the nonworking population $(n=551)$ stratified by weight status: results of the linear regression analysis.

\begin{tabular}{|c|c|c|c|c|c|c|}
\hline & \multicolumn{6}{|c|}{ Association with mental health ${ }^{1}$} \\
\hline & \multicolumn{2}{|c|}{ Crude } & \multicolumn{2}{|c|}{ Adjusted $^{2}$} & \multicolumn{2}{|c|}{ Adjusted $^{3}$} \\
\hline & Beta & $95 \% \mathrm{CI}$ & Beta & $95 \% \mathrm{CI}$ & Beta & $95 \% \mathrm{CI}$ \\
\hline \multicolumn{7}{|l|}{ Healthy weight $(n=165)$} \\
\hline Total & -0.14 & $-0.27 ;-0.01$ & -0.16 & $-0.29 ;-0.03$ & -0.16 & $-0.29 ;-0.02$ \\
\hline Transport (h/wk) & 0.26 & $-0.51 ; 1,02$ & 0.13 & $-0.66 ; 0.91$ & 0.09 & $-0.71 ; 0.89$ \\
\hline (i) Commuting or during work (h/wk) & - & & - & & - & \\
\hline (ii) Leisure (h/wk) & 0.26 & $-0.51 ; 1.02$ & 0.13 & $-0.66 ; 0.91$ & 0.09 & $-0.71 ; 0.89$ \\
\hline At work $(\mathrm{h} / \mathrm{wk})$ & - & & - & & - & \\
\hline Leisure (h/wk) & -0.16 & $-0.29 ;-0.02$ & -0.17 & $-0.30 ;-0.03$ & -0.17 & $-0.30 ;-0.03$ \\
\hline (i) Reading (h/wk) & -0.14 & $-0.38 ; 0.10$ & -0.20 & $-0.46 ; 0.06$ & -0.17 & $-0.45 ; 0.06$ \\
\hline
\end{tabular}


(b) Continued.

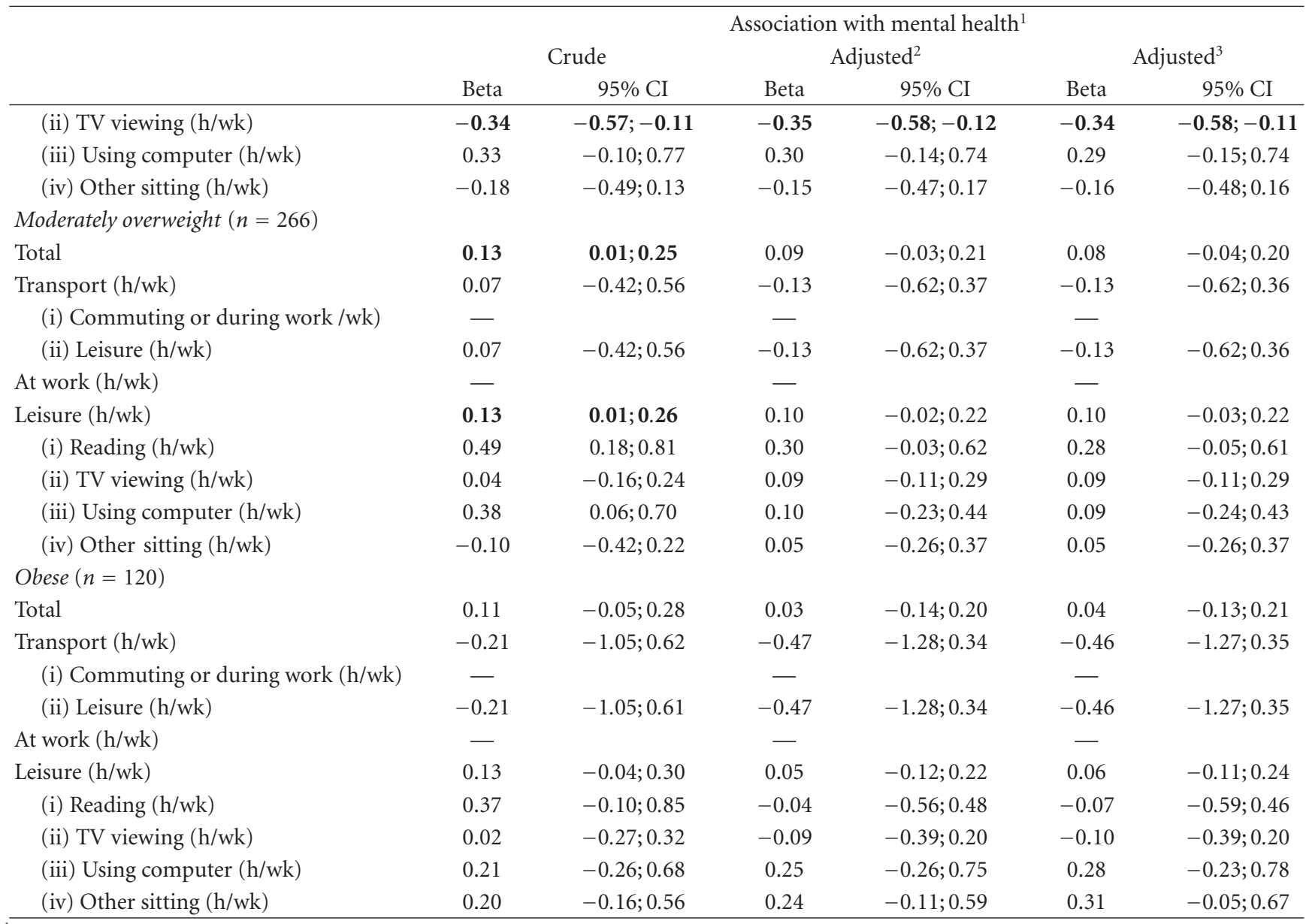

${ }^{1}$ A higher MHI score indicates better mental health; thus, a negative beta indicates a negative association between sitting time and mental health; ${ }^{2}$ adjusted for gender, age, education, household composition, perceived health, physical activity, smoking, and alcohol consumption; ${ }^{3}$ additionally adjusted for BMI.

association between viewing TV and poorer mental health was also apparent among the obese workers only.

There are some mechanisms that may explain a relationship between sitting and the risk for poor mental health. First, the favorable effects of physical activity on mental health, especially on depression, have been well documented $[22,24,34]$. If sedentary behaviors substitute time spent on physical activity, the favorable mental health effects of physical activity cannot occur. The negative association found for overall leisure time and TV viewing with mental health is in line with this mechanism; however, the lack of an association between sitting in general and mental health does not support this explanation. Another mechanism refers to the social withdrawal hypothesis, which proposes a positive association between TV viewing time, removal from social interaction, and a subsequent increased risk of depression [35]. This theory is likely also valid for a general form of mental health problems. The association found in the present study for TV viewing and poorer mental health supports this hypothesis. In addition, the lack of an association for sitting at work and mental health may also support the social withdrawal hypothesis, since most jobs take place within a social context. The finding that the association between sitting and mental health in particular exists for time spent TV viewing might also be explained by the mechanism that TV viewing can be associated with energy-dense snack consumption and snacking behavior, both of which are known to be related to obesity $[20,21]$. Moreover, as a possible explanation, depressive symptoms have been associated with unhealthy food choices, leading to weight gain and, in the longer term, obesity $[36,37]$. Thus, the association between TV viewing and poorer mental health among the obese workers may be explained by the related unhealthy food consumption while viewing TV. All in all, considering the findings that-in case of significant associations-leisure time sitting and especially TV viewing was consistently associated with poorer mental health status, it can be argued that it may be the context of the sitting rather than the length of sitting time that is important in the association with mental health.

A notable finding of our study is the role of weight status with a clear association between the time spent viewing TV and poorer mental health among healthy weight nonworkers as well as among obese workers. A possible explanation for the differing associations found by weight status among workers is that obese workers consume more unhealthy food 
and beverages when viewing TV (compared to the healthy weight and moderate overweight workers), which may make them feel guilty, decrease their self-esteem, and negatively impact their mental well-being. However, it should be emphasized that the current status of knowledge in this field is explorative, and an obvious explanation for the present findings cannot be given. Instead, more research is necessary to investigate the relationships suggested by this explorative study before elaboration.

A few weaknesses and strengths of this study need to be highlighted. First, the data on sedentary behaviors were derived by means of self-report, which challenges reliability and validity [35]. As is well known, subjective methods or self-reports are likely to produce biased measures of the behavior of concern, that is, the amount of sedentary behavior. Because of the increasing awareness of the role of sedentary behavior, it was decided to measure sitting time in the fifth round of the Doetinchem cohort. For the present study, we used sedentary behavior questions that were in line with the structure and format of the physical activity questions. The latter were designed for inclusion in the EPIC study and appeared to be of satisfactory reproducibility and relative validity [28]. Currently, the psychometric characteristics of these sitting questions are unknown, and, until we have better data, future population-based research on sedentary behaviors should develop reliable and valid measurements for various sedentary behaviors. For the present study, we treated the available variables for sitting time rather conservatively, analyzing only respondents with complete data (i.e., no missing values for any variables of sitting time). This helped to ensure a stable dataset. Although the participants were asked to their working status, no further questions on the profession or job roles were included, which can be considered as a limitation of a study. Further, the respondents of the Doetinchem Cohort study may not be fully representative of the Dutch population because respondents live in one (rural) town in the Netherlands and had a very healthy profile with, for instance, a low prevalence of mental illness, which might also have challenged the power of the analyses. The selection of workers may not be compared to the general Dutch working population as the workers in the current study were considerably younger than the nonworkers (who averaged 66 years). This may have resulted in disparate (sedentary) time-spending patterns and health status, simply and solely due to age. However, as the age-adjusted analyses did not show notable differences, we believe the age-related impact on the results is negligible. We examined the associations by linear regression analyses and used a continuous measure for sitting behavior. However, it can be argued that the association between sitting time and mental health is not linear, that is, an increased risk for poorer mental health related to an increase in each weekly sitting hour. Instead, using tertiles or another way of categorizing, the amount of sitting time may have shown significant associations given a certain cutoff point for sitting time. In an additional analysis, we examined the associations for categories of TV viewing $(<2 \mathrm{hr} /$ day versus $\geq 2 \mathrm{hr} /$ day), but this did not change the conclusions (data not shown). It is clear that more research is necessary. First, it is recommended that longitudinal research be performed to confirm the current findings and examine the direction of the relationship. Additionally, it would be more than interesting to test potential behavioral mechanisms. To specify, future research is needed to investigate the mediating role of physical activity, dietary habits, work status, and overweight in the relationship between sedentary behavior and mental health. Finally, as mentioned earlier, the development of reliable and valid measurements covering the entire range of sedentary behaviors is strongly recommended. On the other hand, this study is innovative as it explored the associations between various sedentary behaviors in domains where people spend a substantial part of their day and poor mental health. Another strength is that we used body weight and height, measured by trained and experienced assistants.

In conclusion, the present explorative study confirms the relationship between TV viewing time and poor mental health as suggested in earlier studies, with BMI and working status being effect modifiers, but this association does not hold for spending time in other domains of sitting. Further longitudinal research is needed to confirm the results and to determine the causality in the relationship between sedentary behaviors and mental health. In addition, our data suggest that work status and weight status should be taken into account when studying the relationship between sitting and mental health.

\section{References}

[1] R. E. Andersen, C. J. Crespo, S. J. Bartlett, L. J. Cheskin, and M. Pratt, "Relationship of physical activity and television watching with body weight and level of fatness among children results from the third National Health and Nutrition Examination Survey," Journal of the American Medical Association, vol. 279, no. 12, pp. 938-942, 1998.

[2] M. P. Jans, K. I. Proper, and V. H. Hildebrandt, "Sedentary behavior in dutch workers. Differences between occupations and business sectors," American Journal of Preventive Medicine, vol. 33, no. 6, pp. 450-454, 2007.

[3] W. J. Brown, Y. D. Miller, and R. Miller, "Sitting time and work patterns as indicators of overweight and obesity in Australian adults," International Journal of Obesity, vol. 27, no. 11, pp. 1340-1346, 2003.

[4] T. M. Peters, S. C. Moore, Y. B. Xiang et al., "Accelerometermeasured physical activity in Chinese adults," American Journal of Preventive Medicine, vol. 38, no. 6, pp. 583-591, 2010.

[5] T. N. Robinson, "Reducing children's television viewing to prevent obesity: a randomized controlled trial," Journal of the American Medical Association, vol. 282, no. 16, pp. 1561-1567, 1999.

[6] B. Swinburn and G. Egger, "Preventive strategies against weight gain and obesity," Obesity Reviews, vol. 3, no. 4, pp. 289-301, 2002.

[7] A. Lake and T. Townshend, "Obesogenic environments: exploring the built and food environments," Journal of The Royal Society for the Promotion of Health, vol. 126, no. 6, pp. 262-267, 2006.

[8] D. M. Williams, H. A. Raynor, and J. T. Ciccolo, "A review of TV viewing and its association with health outcomes in 
adults," American Journal of Lifestyle Medicine, vol. 2, pp. 250 259, 2008.

[9] J. A. Foster, S. A. Gore, and D. S. West, "Altering TV viewing habits: an unexplored strategy for adult obesity intervention?" American Journal of Health Behavior, vol. 30, no. 1, pp. 3-14, 2006.

[10] M. J. Chinapaw, K. I. Proper, J. Brug, W. van Mechelen, and A. S. Singh, "Relationship between young peoples' sedentary behaviour and biomedical health indicators: a systematic review of prospective studies," Obesity Reviews, vol. 12, no. 7, pp. e621-e632, 2011.

[11] K. I. Proper, A. S. Singh, W. van Mechelen, and M. J. Chinapaw, "Sedentary behaviors and health outcomes among adults: a systematic review of prospective studies," American Journal of Preventive Medicine, vol. 40, no. 2, pp. 174-182, 2011.

[12] J. G. Z. Van Uffelen, J. Wong, J. Y. Chau et al., "Occupational sitting and health risks: a systematic review," American Journal of Preventive Medicine, vol. 39, no. 4, pp. 379-388, 2010.

[13] M. Hamer, E. Stamatakis, and G. D. Mishra, "Televisionand screen-based activity and mental well-being in adults," American Journal of Preventive Medicine, vol. 38, no. 4, pp. 375-380, 2010.

[14] M. Teychenne, K. Ball, and J. Salmon, "Sedentary behavior and depression among adults: a review," International Journal of Behavioral Medicine, vol. 17, no. 4, pp. 246-254, 2010.

[15] M. Teychenne, K. Ball, and J. Salmon, "Physical activity, sedentary behavior and depression among disadvantaged women," Health Education Research, vol. 25, no. 4, pp. 632 644,2010

[16] M. H. Ussher, C. G. Owen, D. G. Cook, and P. H. Whincup, "The relationship between physical activity, sedentary behaviour and psychological wellbeing among adolescents," Social Psychiatry and Psychiatric Epidemiology, vol. 42, no. 10, pp. 851-856, 2007.

[17] A. P. Sihvonen, Documentation Sheet: Psychological Distress, European Community Health Indicators Monitoring, 2008.

[18] M. Driessen, "Geestelijke ongezondheid in Nederland in kaart gebracht-Een beschrijving van de MHI-5 in de gezondheidsmodule van het Permanent Onderzoek Leefsituatie," Den haag/Heerlen: Centraal Bureau voor de Statistiek, 2011.

[19] M. Hamer, E. Stamatakis, and G. Mishra, "Psychological distress, television viewing, and physical activity in children aged 4 to 12 years," Pediatrics, vol. 123, no. 5, pp. 1263-1268, 2009.

[20] M. Thomson, J. C. Spence, K. Raine, and L. Laing, "The association of television viewing with snacking behavior and body weight of young adults," American Journal of Health Promotion, vol. 22, no. 5, pp. 329-335, 2008.

[21] C. A. Vereecken, J. Todd, C. Roberts, C. Mulvihill, and L. Maes, "Television viewing behaviour and associations with food habits in different countries," Public Health Nutrition, vol. 9, no. 2, pp. 244-250, 2006.

[22] M. Teychenne, K. Ball, and J. Salmon, "Physical activity and likelihood of depression in adults: a review," Preventive Medicine, vol. 46, no. 5, pp. 397-411, 2008.

[23] F. S. Luppino, L. M. De Wit, P. F. Bouvy et al., "Overweight, obesity, and depression: a systematic review and meta-analysis of longitudinal studies," Archives of General Psychiatry, vol. 67, no. 3, pp. 220-229, 2010.

[24] G. Windle, D. Hughes, P. Linck, I. Russell, and B. Woods, "Is exercise effective in promoting mental well-being in older age?
A systematic review," Aging and Mental Health, vol. 14, no. 6, pp. 652-669, 2010.

[25] G. Gariepy, D. Nitka, and N. Schmitz, "The association between obesity and anxiety disorders in the population: a systematic review and meta-analysis," International Journal of Obesity, vol. 34, no. 3, pp. 407-419, 2010.

[26] W. M. M. Verschuren, H. A. Smit, E. M. van Leer et al., "Prevalence of and changes in risk factors for cardiovascular diseases over the period 1987-1991," Final Report of the Monitoring Project on Cardiovascular Disease Risk Factors 1987-1991, Rijkstinstituut voor Volksgezondheid en Milieu, Bilthoven, The Netherlands, 1994.

[27] W. M. M. Verschuren, A. Blokstra, H. S. J. Picavet, and H. A. Smit, "Cohort profile: the Doetinchem Cohort Study," International Journal of Epidemiology, vol. 37, no. 6, pp. 12361241, 2008.

[28] M. A. Pols, P. H. M. Peeters, M. C. Ocké, N. Slimani, H. B. Bueno-De-Mesquita, and H. J. A. Collette, "Estimation of reproducibility and relative validity of the questions included in the EPIC Physical Activity Questionnaire," International Journal of Epidemiology, vol. 26, supplement 1, pp. S181-S189, 1997.

[29] K. I. Van der Zee and R. Sanderman, Het Meten van Gezondheidstoestand Met de RAND-36: een Handleiding, Noordelijk Centrum voor Gezondheidsvraagstukken, Groningen, The Netherlands, 1993.

[30] K. I. VanderZee, R. Sanderman, J. W. Heyink, and H. De Haes, "Psychometric qualities of the RAND 36-item health survey 1.0: A multidimensional measure of general health status," International Journal of Behavioral Medicine, vol. 3, no. 2, pp. 104-122, 1996.

[31] R. Perenboom, K. Oudshoorn, L. van Herten et al., LifeExpectancy in Good Mental Health: Establishing Cut-off Points for the MHI-5 and GHQ-12, Leiden Netherlands Organisation for Applied Scientific Research, 2000.

[32] B. E. Ainsworth, W. L. Haskell, M. C. Whitt et al., "Compendium of physical activities: an update of activity codes and MET intensities," Medicine and Science in Sports and Exercise, vol. 32, supplement 9, pp. S498-S504, 2000.

[33] H. G. C. Kemper, W. T. M. Ooijendijk, and M. Stiggelbout, "Consensus over de nederlandse norm voor gezond bewegen," Tijdschrift voor Sociale Gezondheidszorg, vol. 78, pp. 180-183, 2000.

[34] P. J. Carek, S. E. Laibstain, and S. M. Carek, "Exercise for the treatment of depression and anxiety," International Journal of Psychiatry in Medicine, vol. 41, no. 1, pp. 15-28, 2011.

[35] R. Kraut, M. Patterson, V. Lundmark, S. Kiesler, T. Mukopadhyay, and W. Scherlis, "Internet Paradox: a social technology that reduces social involvement and psychological wellbeing?" American Psychologist, vol. 53, no. 9, pp. 1017-1031, 1998.

[36] H. Konttinen, S. Männistö, S. Sarlio-Lähteenkorva, K. Silventoinen, and A. Haukkala, "Emotional eating, depressive symptoms and self-reported food consumption. A populationbased study," Appetite, vol. 54, no. 3, pp. 473-479, 2010.

[37] E. L. Gibson, "Emotional influences on food choice: sensory, physiological and psychological pathways," Physiology and Behavior, vol. 89, no. 1, pp. 53-61, 2006. 


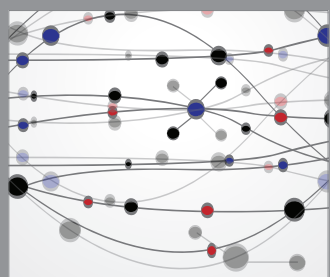

The Scientific World Journal
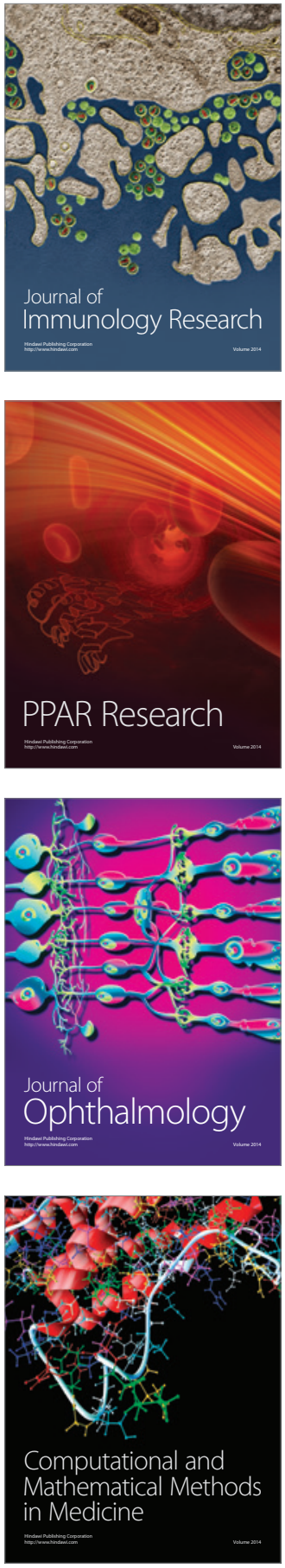

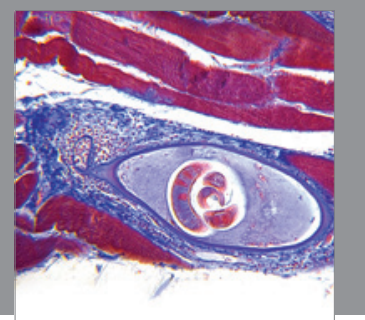

Gastroenterology

Research and Practice
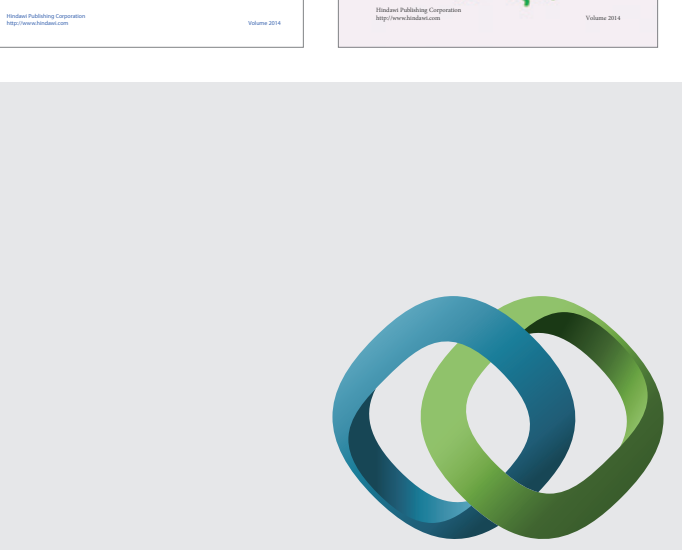

\section{Hindawi}

Submit your manuscripts at

http://www.hindawi.com
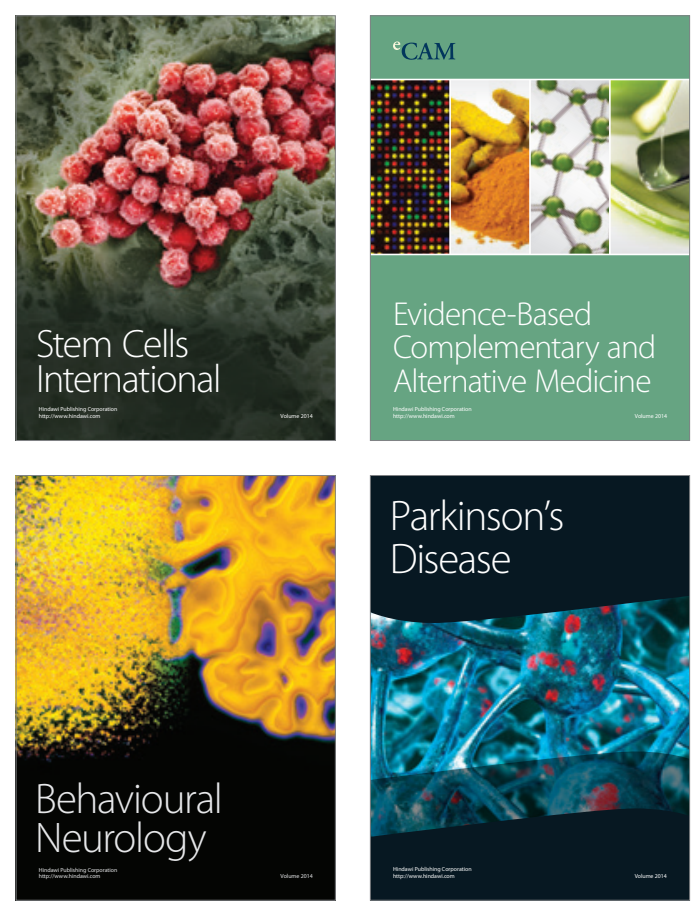

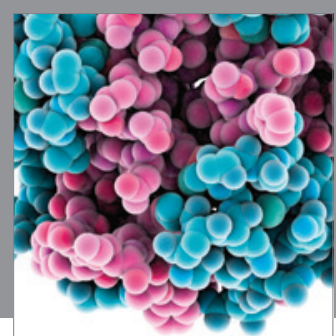

Journal of
Diabetes Research

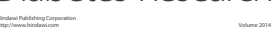

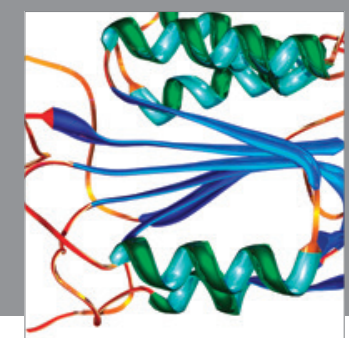

Disease Markers
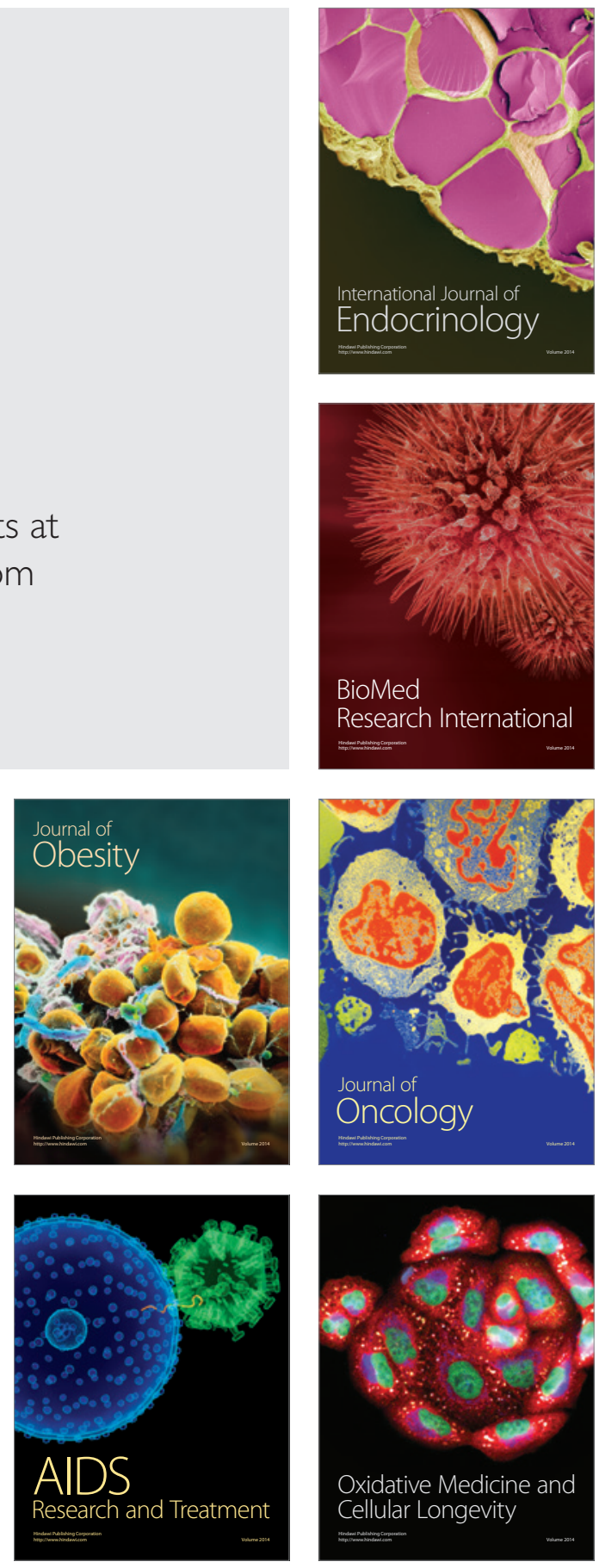